Miami Nature Biotechnology Short Reports

TheScientificWorld (2001) 1(S3), 107SR

ISSN 1532-2246; DOI 10.1100/TSW.2001.121

\title{
PAN-CASPASE INHIBITOR PREVENTS ANTI-CD3 MEDIATED T-LYMPHOCYTE PROLIFERATION
}

\author{
Raja S. Mahidhara*, R. Hoffman, R.L. Simmons, and T.R. Billiar \\ Department of Surgery, University of Pittsburgh School of Medicine, W1503 Biomedical Science \\ Tower, 200 Lothrop St., Pittsburgh, PA 15261 \\ * mahidharar@msx.upmc.edu
}

BACKGROUND. Host defense requires the ability for upregulation and downregulation of lymphocyte responses. It is well known that proliferative responses can be seen in conjunction with subsequent cell death suggesting that the two processes are linked.(1) Caspases are constitutively expressed zymogens which, upon activation, participate in receptor and nonreceptor mediated apoptosis.(2) The purpose of this study was to assess whether caspase activity was required for the proliferation of splenic-derived T lymphocytes by using the nonspecific, irreversible inhibitor z-VAD-fmk.

METHODS. Splenocytes from C57Bl/6 mice were passed over an antibody coated column (R\&D) to obtain a $>90 \%$ CD3+ population. Cells were stimulated to proliferate with immobilized monoclonal anti-CD3 (BD Pharmingen, $100 \mu \mathrm{g} / \mathrm{ml}$ ) in 10\% MLC media. Proliferation was assessed by ${ }^{3} \mathrm{H}$ thymidine incorporation at time points with and without $\mathrm{z}$ VAD-fmk (Alexis, $100 \mu \mathrm{M}$ ). Western Blot analysis was performed by SDS-PAGE and probed with polyclonal Caspase 3 antibody H-277 (Santa Cruz, 1:1000). Caspase 3-like activity was assessed by $100 \mu \mathrm{M}$ Ac-DEVD-pNA (Alexis) substrate followed by quantitation by spectrophotometry at $405 \mathrm{~nm}$.

RESULTS. TCR stimulation of purified T lymphocytes at 72 hours resulted in proliferation 500 fold greater than unstimulated controls. Treatment of lymphocytes with zVAD inhibited CD3 mediated proliferation by greater than 99\%. Delay in the administration of inhibitor after stimulation decreased the effect on proliferation (see Figure 1). 


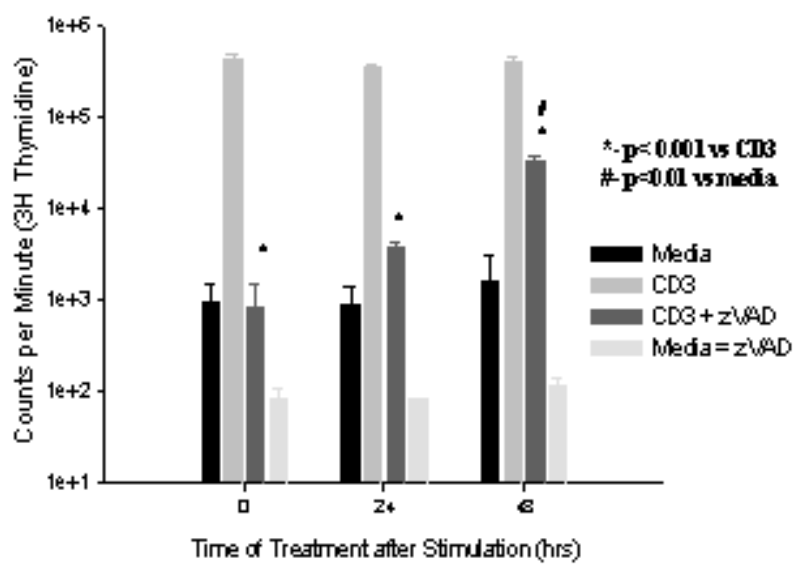

Western blot revealed the appearance of the $17 \mathrm{kD}$ active form of caspase 3 after 48 hours of stimulation (data not shown). Caspase 3-like activity was similarly seen to increase over time after stimulation to greater than 3 -fold over control by $72 \mathrm{hrs}$. Change in $\mathrm{OD} / \mathrm{mg} / \mathrm{hr}$ went from 2.0 at time 0 to 4.8 at 24 hours and 6.3 by 72 hrs (Figure 2).

Figure 2. DEVD like activity in CD3 stimulated Haive $T$ cells

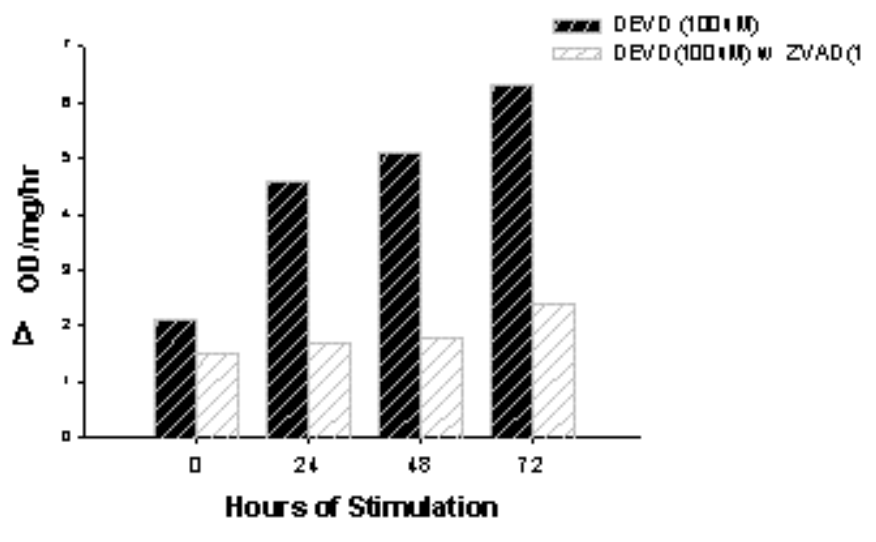

DISCUSSION. Experiments in this study have shown that the non-specific caspase inhibitor, $\mathrm{z}-\mathrm{VAD}$, inhibits polyclonal stimulation of naïve, murine spleen derived $\mathrm{T}$ lymphocytes. Stimulation of lymphocytes is associated with time dependent expression of the active fragment of caspase 3, a central effector molecule in the apoptotic pathway. Importantly function of caspase 3 was observed by enzyme activity and seen to increase in a time dependent manner with stimulation.

Members of the caspase family of cysteine proteases have been known to be intimately involved with a variety of essential steps in lymphocyte apoptosis. We show that these molecules may also be involved with proliferative responses. Regulation of caspase signaling 
may be an important link in understanding the link between proliferation and cell death after $\mathrm{T}$ cell stimulation.

ACKNOWLEDGEMENTS. This work was supported by Society of Thoracic Surgeons Research Fellowship (RSM) and the NIH RO1-GM-44100 (TRB).

\section{REFERENCES.}

1. Lenardo, M. et al. (1999) Annu. Rev. Immunol. 17, 221-253

2. Budihardjo, I. et al. (1999) Annu. Rev. Cell Dev. Biol. 15, 269-290 

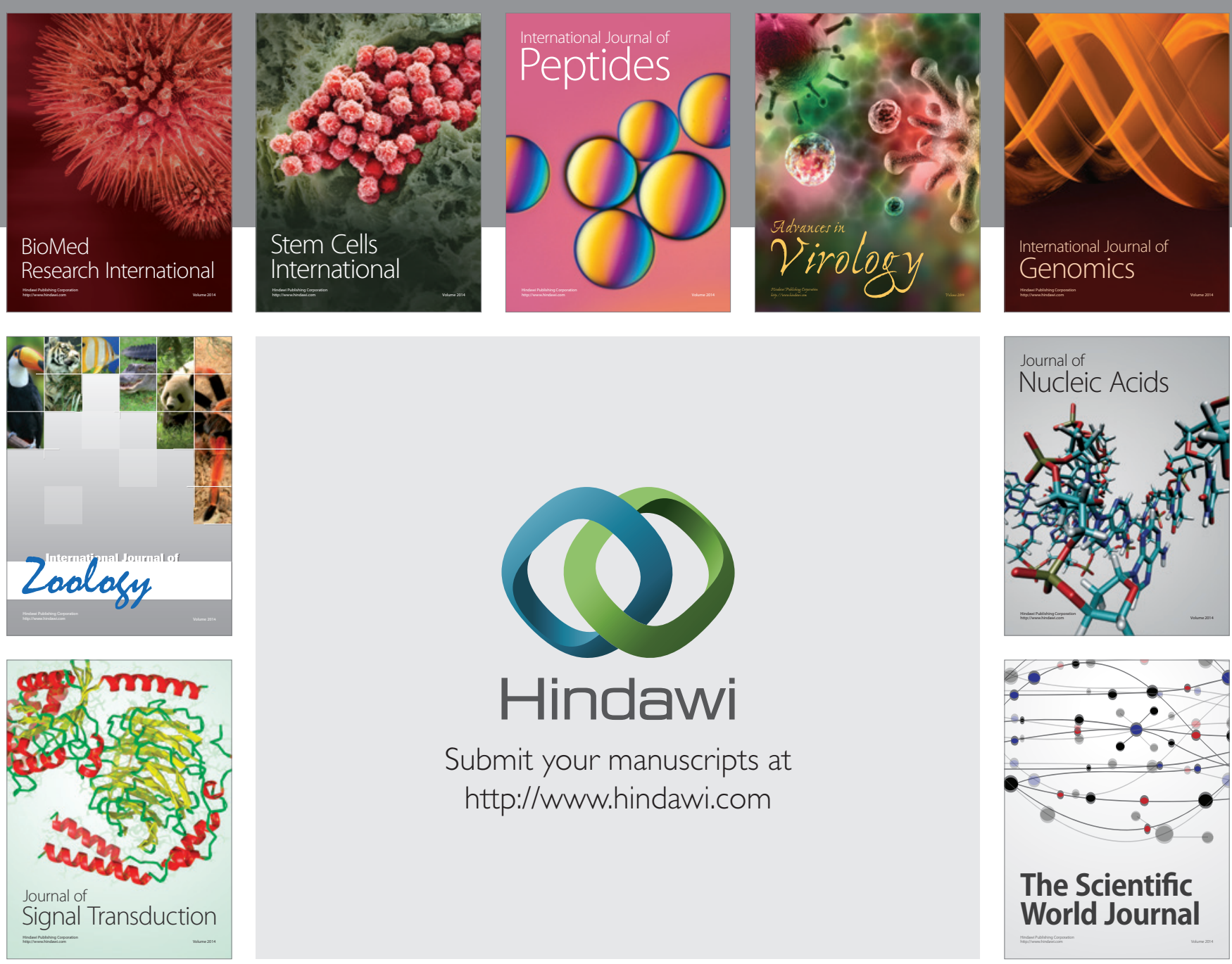

Submit your manuscripts at

http://www.hindawi.com
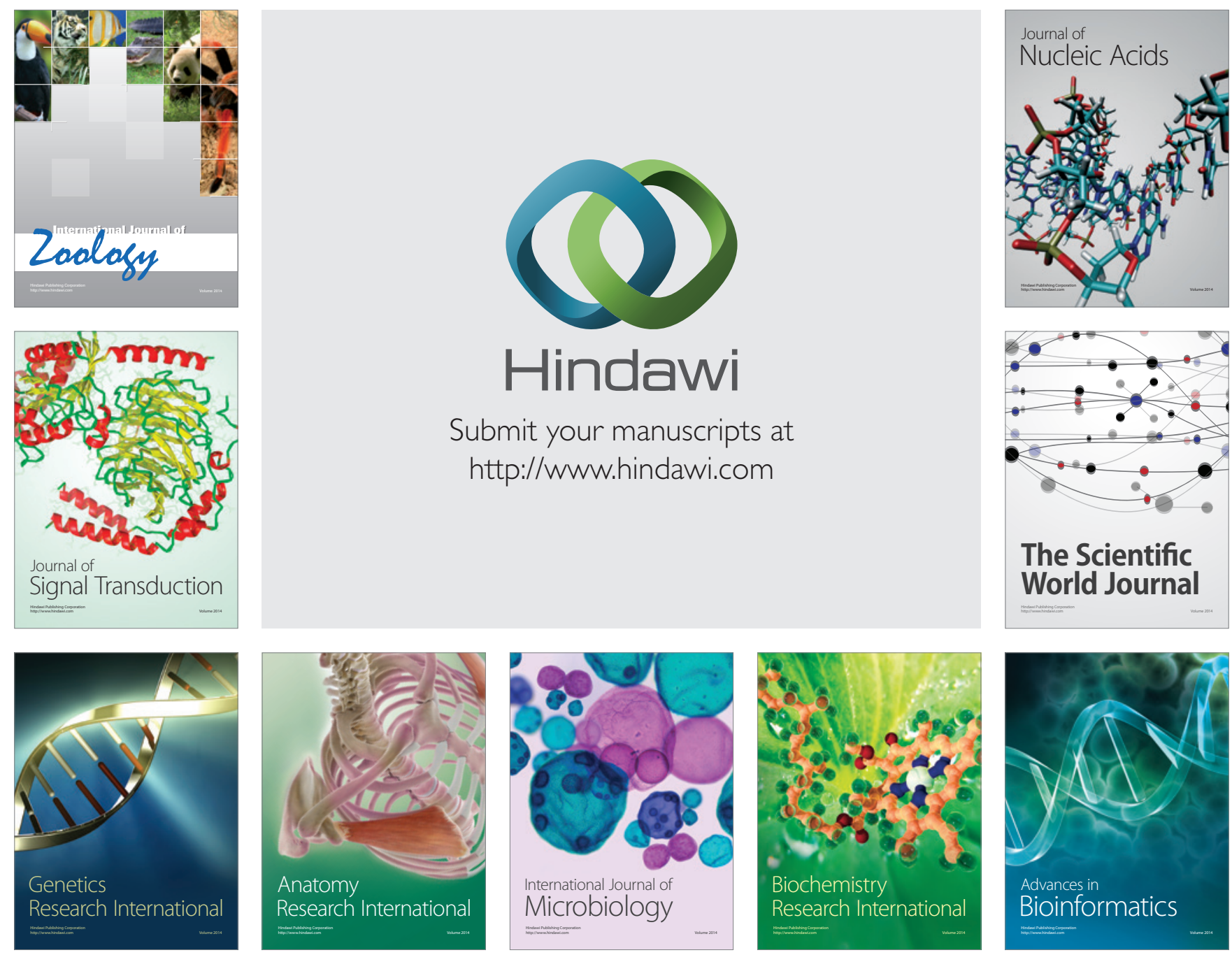

The Scientific World Journal
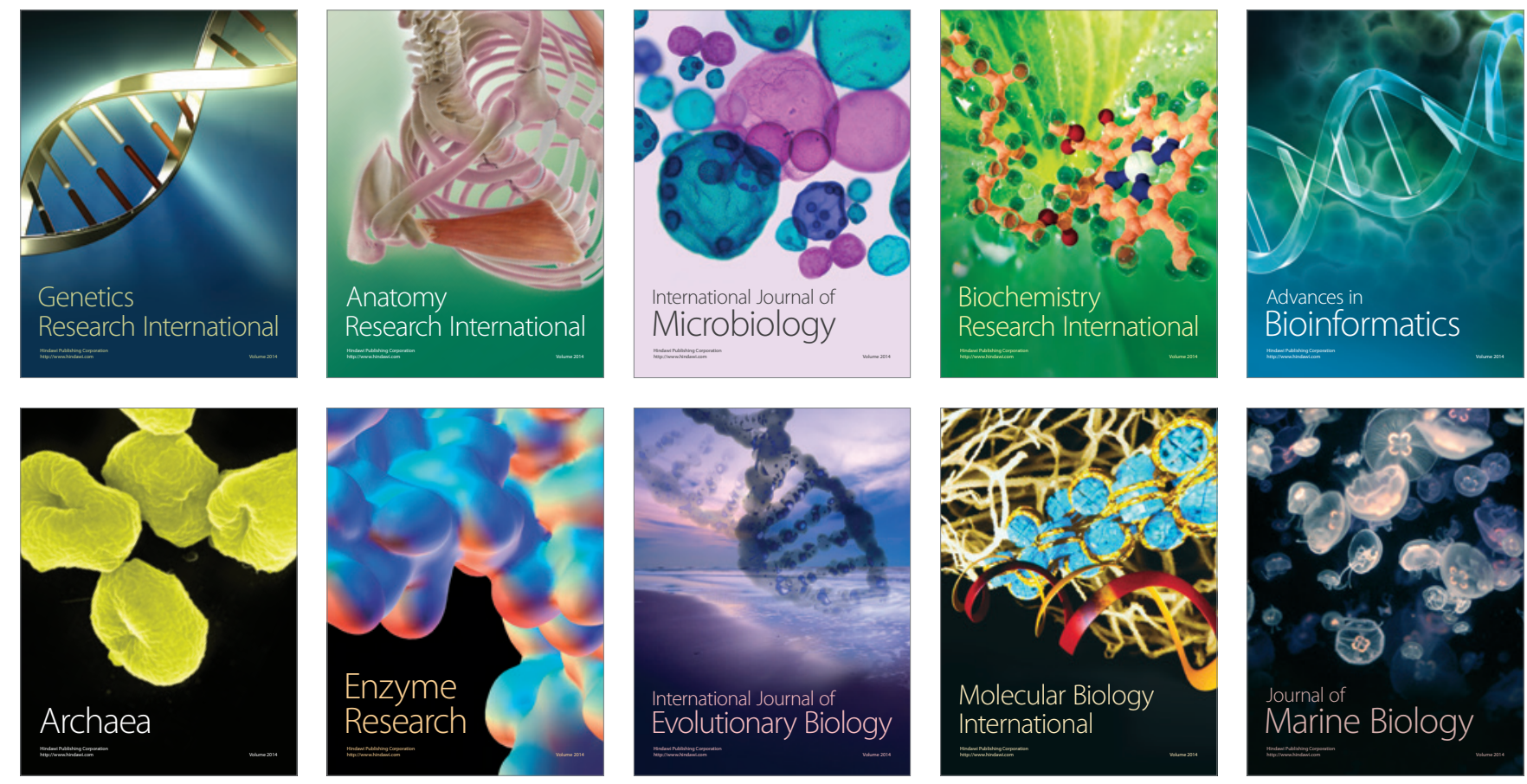